INNOVACIÓN

\title{
Os saberes mobilizados pelo bom professor na visão de alunos concluintes do curso de direito
}

\author{
The knowledge mobilized by the good professor in the vision of students \\ concluding the course of law
}

\author{
Adilson José Ribeiro \\ Universidade Associação Educacional Leonardo Da Vinci, Brasil
}

Rita Buzzi Rausch

Universidade Regional de Blumenau, Brasil

\begin{abstract}
RESUMO O presente artigo apresenta os resultados de uma pesquisa que objetivou compreender, por meio dos dizeres dos alunos do Curso de Direito da Universidade Regional de Blumenau - FURB, suas percepções acerca do bom professor para o Curso de Direito. A coleta de dados foi realizada com setenta e três alunos concluintes do curso, por meio de um questionário, com a utilização da técnica do complemento. A pesquisa foi de cunho qualitativo e a análise de conteúdo dos dados pautou-se principalmente nos estudos de Clermont Gauthier, Álvaro Marchesi, Claude Lessard, Maurice Tardif, António Nóvoa e Paulo Freire. Em conclusão, os resultados permitiram inferir que para os alunos do Curso de Direito o bom professor mobiliza um conjunto de saberes no contexto educacional em que atua, em especial, os saberes pedagógicos, disciplinares, curriculares e experienciais. Bem como, evidenciou-se que a relação afetiva-emocional é de grande importância na prática do bom professor, pois, esta dimensão é tão vital quanto os saberes científicos, as estratégias de aprendizagem, o compromisso social e moral dos docentes.
\end{abstract}

PALAVRAS-CHAVE Saberes docentes, Professor Universitário, Professor da área do Direito.

ABSTRACT This article presents the results of a research that aimed to understand, through the words of the students of the Law Course of the Universidade Regional de Blumenau - FURB, their perceptions about the good teacher for the Law Course. Data collection was performed with seventy-three students completing the course, through a questionnaire, using the complement technique. The research was qualitative and data 
content analysis was based mainly on the studies of Clermont Gauthier, Álvaro Marchesi, Claude Lessard, Maurice Tardif, António Nóvoa and Paulo Freire. In conclusion, the results allowed to infer that for the students of the Law Course the good professor mobilizes a set of knowledge in the educational context in which it acts, especially, the pedagogical, disciplinary, curricular and experiential knowledge. As well, it was evidenced that the affective-emotional relationship is of great importance in the practice of the good professor, because this dimension is as vital as the scientific knowledge, the learning strategies, the social and moral commitment of the teachers.

KEY WORDS: Teaching Knowledge, College Professor, Professor of Law.

\section{Introdução}

Todas as profissões são calcadas por um conjunto de conhecimentos e saberes necessários para a execução de suas atividades. Ao contrário de outros ofícios que estruturam um conjunto de saberes, os profissionais do ensino de modo geral descuidam deste ponto, transformando o habitat escolar em um local repleto de caixas pretas, onde poucos conhecem o que é necessário saber para ensinar, tendo em vista que vivemos ainda em um tempo onde o ofício docente é envolto em uma «cegueira conceitual».(Gauthier et al, 2006:20)

A prática profissional do professor não é um mero ofício de aplicação de teorias; é, sim, um espaço de produção de saberes e conhecimentos para o seu desenvolvimento profissional e sua emancipação. Esses saberes provêm de diferentes fontes e dão origem a um saber múltiplo, plural, «formado pelo amálgama, mais ou menos coerente, de saberes oriundos da formação profissional e de saberes disciplinares, curriculares e experienciais».(Tardif, 2008:36)

Neste sentir, é necessário entender que para os docentes desenvolverem suas atividades, é imprescindível um conjunto de conhecimentos que «formam uma espécie de reservatório no qual o professor se abastece para responder a exigências específicas de sua situação concreta de ensino» (Gauthier et al, 2006:77-78). Esses conhecimentos ligados ao fazer pedagógico constituem um desafio à profissionalização docente, que constituem os saberes que são mobilizados pelo professor em sua prática cotidiana. (Badia, Gómez, 2014; Torello, 2014; Más-Torelló, 2016; Silva et al, 2015; Casero, 2010; Roncancio et al, 2013)

Gauthier (2006:28) denominam esses saberes de: saber disciplinar aquele produzido pelos pesquisadores nas diversas áreas do conhecimento, conceitos e métodos relativos a uma disciplina; saber curricular é o saber que a escola como instituição seleciona e organiza para ser ensinado nos programas/currículos escolares; saberes das ciências da educação refere-se aos saberes que todo professor adquire durante a sua formação a respeito da educação e do seu ofício; saberes da tradição pedagógica 
diz respeito ao saber das aulas e estão relacionados com a representação que previamente cada professor tem da escola e serão adaptados pelo saber experiencial do dia-a-dia da prática pedagógica; saber da ação pedagógica é o saber experiencial dos professores que é testado com pesquisas realizadas em sala de aula, as quais, ao serem socializadas, podem servir de apoio e ação para outros professores; saber experiencial é um saber que se limita às experiências de cada professor em sua sala de aula ao longo da sua carreira, feito de pressupostos não verificados cientificamente.

Desta forma, não basta o professor conhecer o conteúdo, ter talento, bom senso, seguir a intuição, ter experiência ou ainda possuir uma vasta cultura, mesmo que estes enunciados esbocem certa dose de realidade, mas estes mesmos enunciados impedem a manifestação de saberes profissionais específicos do trabalho docente o que provoca na maioria das vezes um «estéril amadorismo» no exercício da docência, o que impede de certa forma a profissionalização da profissão. (Gauthier et al, 2006:20-25)

Diante dessa diversidade e complexidade de saberes docentes, o objetivo central deste artigo é compreender, por meios dos dizeres dos alunos do curso de Direito da Universidade Regional de Blumenau - FURB, as suas percepções sobre o bom professor do Curso de Direito. (Pérez, 2017)

Para se atingir tal objetivo, buscamos nos afastar da utilização de intermináveis listagens de competências, o que invariavelmente se tornaria cansativo e não aprofundaria a questão central. Contudo, é possível esboçar alguns apontamentos, alguns caminhos para o trabalho do bom professor, principalmente visto como uma «disposição», como uma busca por uma real e verdadeira identidade profissional. (Nóvoa, 2009:28)

Nóvoa, ainda nos auxilia nesta busca pelo bom professor destacando

[...] Durante muito tempo, procuraram-se os atributos ou as características que definiam o «bom professor». Esta abordagem conduziu, já na segunda metade do século XX, à consolidação de uma trilogia que teve grande sucesso: saber (conhecimentos), saber-fazer (capacidades), saber-ser (atitudes). Nos anos 90 foi-se impondo um outro conceito, competências, que assumiu um papel importante na reflexão teórico e, sobretudo, nas reformas educativas. Todavia, apesar de inúmeras reelaborações, nunca conseguiu libertar-se das suas origens comportamentalistas e de leituras de cariz técnico e instrumental. Não espanta, por isso, que se tenha adaptado tão bem às políticas da "qualificação dos recursos humanos», da «empregabilidade» e da «formação ao longo da vida», adquirindo uma grande visibilidade nos textos das organizações internacionais, em particular da União Europeia. Ao sugerir um novo conceito, disposição, pretendo romper com um debate sobre as competências que me parece saturado. Adopto um conceito mais «liquído» e menos «sólido», que pretende olhar preferencialmente para a ligação entre as dimensões pessoais e profissionais na produção identitária dos professores. (Nóvoa, 2009: 29) 
Para concluir o seu entendimento, Nóvoa (2009:30-31) apresenta as cinco facetas ou as cinco «disposições» do bom professor: «conhecimento, cultura profissional, tacto pedagógico, trabalho em equipa e compromisso social» que juntos corroboram para a construção de uma identidade profissional.

Entendemos que a necessidade de investigar as percepções dos alunos sobre o bom professor, possibilita obtermos pistas para uma melhor compreensão do papel docente e dos saberes que movimentam o seu cotidiano em sala de aula.

Participaram desta pesquisa 73 (setenta e três) alunos concluintes no $1^{\circ}$ e $2^{\circ}$ semestre de 2011 do curso de Direito da Universidade Regional de Blumenau - FURB. A recolha dos dados foi articulada por meio da aplicação de um questionário para os acadêmicos contendo 5 (cinco) tópicos: a) idade; b) sexo; c) formação acadêmica; d) nominar o melhor professor do curso de Direito da FURB; e) justificar a escolha deste professor.

O questionário foi aplicado para os alunos que estavam presentes na sala de aula, no turno matutino e noturno das turmas concluintes, respectivamente em maio e outubro de 2011, na presença do pesquisador. Para a realização desta pesquisa foi utilizado a técnica de complemento, em que o pesquisador apresenta ao respondente um estímulo a ser preenchido por meio de palavras. Ao preenche-lo, o respondente geralmente revela motivações, crenças e sentimentos que dificilmente seriam manifestados por meios convencionais de geração de dados, como por exemplo: questionários ou entrevistas.

As justificativas dos acadêmicos para a escolha do bom professor foram analisadas e classificadas à luz das ideias centrais de Clermont Gauthier, Maurice Tardif, Claude Lessard, Álvaro Marchesi, António Nóvoa e Paulo Freire.

Agrupamos os dados obtidos em quatro categorias, conforme apresentado por Maurice Tardif (2008:36) como os saberes oriundos da formação pedagógica (saber pedagógico), saber disciplinar, curricular e experiencial, vejamos agora cada um deles.

\section{O saber pedagógico}

Os saberes pedagógicos são construídos pelo professor por meio da ação combinada entre teoria e prática, pois são articulados na relação com os alunos em sua prática cotidiana. Maurice Tardif esclarece que a atividade docente não se trata de um objeto do saber das ciências da educação, mas mobiliza diversos saberes que se chamam de pedagógicos, onde

[...] Os saberes pedagógicos apresentam-se com doutrinas ou concepções provenientes de reflexões sobre a prática educativa no sentido amplo do termo, reflexões racionais e normativas que conduzem a sistemas mais ou menos coerentes de representação e de orientação da atividade educativa. (Tardif, 2008:37) 
O professor enfrenta na sala de aula diversos contextos que são complexos por natureza, assim o docente necessita lançar mão dos conhecimentos que possui de uma forma original e criativa para formar uma interação organizada e intencional do saber científico que será dialogado e construído em sala de aula.

Neste sentido o saber pedagógico é reconhecido pelos alunos com um importante ingrediente na prática profissional do docente. $\mathrm{O}$ aluno A44 ressalta que o bom professor é reconhecido pelo «comprometimento em ensinar, pelos métodos utilizados em sala (método de ensino), pela explicação da matéria todas as vezes que surgi alguma dúvida. Este professor explica com clareza a matéria, de forma objetiva, sem humilhar o aluno quando este faz perguntas em sala de aula.» Para o aluno A62 «[...] um bom professor não se faz somente pelos diplomas, devem ter didática para atrair os alunos. O professor em especial sabe muito bem como fazer uma aula ser boa em conteúdo, fazendo os alunos tenham vontade de participar.»

O saber pedagógico é o saber que o docente produz no cotidiano de seu trabalho e que fundamenta sua prática docente. É o saber que permite ao professor interagir com os estudantes, no contexto da sala de aula, no cotidiano em que atua.

Inferimos pelos dizeres dos discentes que os professores são profundos conhecedores de conteúdos específicos, mas igualmente necessitam serem peritos em como organizar e sistematizar os conteúdos, pois, o saber pedagógico é a forma do como e porque ensinar determinado conteúdo disciplinar.

Ademais, o trabalho docente exige uma qualificação que vai além das capacidades e conhecimentos dos outros trabalhadores, tendo em vista que o professor é corresponsável pelo cotidiano da sala de aula, onde conhecimento, saber pedagógico e compromisso com o processo de ensino-aprendizagem são a tônica do seu trabalho. (Tardif, 2008:43) Neste sentido, o aluno A63 reforça que o bom professor possui uma "[...] didática que facilita a aprendizagem. É comunicativo, interage com os alunos no decorrer das aulas.» $\mathrm{O}$ que se evidencia por esta fala é que a ação docente deve centralizar seus esforços na aprendizagem dos alunos, deve instigar a busca pelo processo de conhecer, pois este é o objetivo da escola. Nóvoa esclarece que o «trabalho escolar tem duas grandes finalidades: por um lado, a transmissão e apropriação dos conhecimentos e da cultura; por outro lado, a compreensão da arte do encontro, da comunicação e da vida em conjunto.» (Nóvoa, 2009: 62)

Desta forma, o bom professor deve equilibrar o conhecimento com o modo de ensinar, ou seja, deve encontrar mecanismos para tornar o saber científico compreensível para o aluno, de modo a agrupar e coordenar as atividades de aprendizagem, com diferentes estratégias, explanações, questionamentos e discussões.

\section{O saber disciplinar}

Parece bastante óbvio, mas o professor de modo geral necessita ser conhecedor da 
disciplina que se propõe a dialogar com os alunos, pois, é impensável conduzir uma atividade complexa como a articulada em sala de aula, sem dominar os ingredientes que compõe a história, fundamentação teórica, carga sociológica, filosófica e política da disciplina que será ministrada.

Tardif esclarece que

[...] Além dos saberes produzidos pelas ciências da educação e dos saberes pedagógicos, a prática docente incorpora ainda saberes sociais definidos e selecionados pela instituição universitária. Estes saberes integram-se igualmente à prática docente através da formação (inicial e contínua) dos professores nas diversas disciplinas oferecidas pela universidade. Podemos chamá-las de saberes disciplinares. São saberes que correspondem aos diversos campos do conhecimento, aos saberes de que dispõe a nossa sociedade, tais como se encontram hoje integrados nas universidades, sob a forma de disciplinas, no interior de faculdades e de cursos distintos. (Tardif,2008: 38)

Neste sentido, os alunos reconhecem a necessidade de o professor ser profundo conhecedor da disciplina que vai lecionar, pois o saber escolar está fortemente ancorado no conteúdo disciplinar. Assim, para o aluno A7 o bom professor é aquele que «contribuiu para o desenvolvimento do acadêmico, sendo um conhecedor profundo da disciplina que leciona.» Nessa perspectiva, o bom professor deve compreender as particularidades «do lado de dentro» da disciplina que se propõe a ministrar, pois, a primeira base intelectual de um profissional do ensino, é o domínio consistente da estrutura substantiva e sintática da matéria que leciona. (Gimeno Sacristán, 1998:27)

O professor necessita levar a sério seus estudos, suas pesquisas, seu ofício, tendo em vista que a carência de conhecimentos provoca uma espiral de incompetência que destrói moralmente o professor no seu espaço escolar. Neste sentido, o «professor que não leva a sério sua formação, que estude, que não se esforce para estar à altura de sua tarefa não tem força moral para coordenar as atividades de sua classe. [...] O que quero dizer é que a incompetência profissional desqualifica a autoridade do professor.»(Freire, 2009:92)

Ademais, Freire reforça o cuidado que a educação exige, pois, é uma forma de intervenção no mundo. Nas suas palavras, este é «outro saber que não posso duvidar um momento sequer na minha prática educativo-crítica é o de que, como experiência especificamente humana, a educação é uma fonte de intervenção no mundo.»(Freire, 2009:98)

Entendimento que se reforça com os dizeres do aluno A29 que o bom professor "além do conhecimento teórico, traz para a sala de aula pensamentos críticos sobre a disciplina e sobre a sociedade em geral. O método de dar aula é interessante, pois ela atrai a atenção e consegue demonstrar vários pontos de vistas a respeito dos assuntos abordados.» Para o aluno A30 o bom professor «demonstra pleno domínio da matéria, 
conseguem 'prender' a atenção dos acadêmicos, tem seriedade, sem ser maçante, avalia o conteúdo conforme o que foi ministrado nas aulas. Com este professor, assimilei mais conhecimento.» Entendemos que o docente necessita demonstrar domínio do conteúdo que se propõe a dialogar com seus alunos, bem como, a compreensão do seu papel

[...] ao falar com clareza sobre o objeto, é incitar o aluno a fim de que ele, com os materiais que ofereço, produza a compreensão do objeto em lugar de recebê-la, na integra, de mim. Ele precisa se apropriar da inteligência do conteúdo para que a verdadeira relação de comunicação entre mim, como professor, e ele, como aluno se estabeleça. É por isso, repito, que ensinar não é memorizar o perfil do conteúdo transferido no discurso vertical do professor. Ensinar e aprender têm que ver com o esforço metodicamente crítico do professor de desvelar a compreensão de algo e com o empenho igualmente crítico do aluno de ir entrando como sujeito em aprendizagem, no processo que o professor ou professora deve deflagrar. Isso não tem nada que ver como a transferência de conteúdo e fala da dificuldade mas, ao mesmo tempo, com a boniteza da docência e a discência. (Freire, 2009:118)

Os sujeitos da pesquisa reconheceram a necessidade do conhecimento disciplinar específico da ciência jurídica. Partindo destes dizeres, encontramos aproximações com o pensamento de Tardif (2008:39), quando estabelece que o «professor ideal é quem conhece sua matéria, sua disciplina e seu programa, além disso, apresenta conhecimentos relativos a ciências da educação e da pedagogia, e acaba desenvolvendo um saber prático tendo como referência a sua experiência cotidiana com os alunos».

Desta forma, para ensinar é preciso saber o conteúdo disciplinar integrado com outros saberes inerentes ao ofício docente e lembrar que «ensinar não é transferir conhecimento, mais criar as possibilidades para a sua própria produção ou a sua construção.»(Freire, 2009:47)

Conhecer a matéria é inerente a prática profissional do professor, contudo é igualmente necessário ter consciência de que se lida com gente e não com máquinas, objetos ou simplesmente nomes impressos em um diário de classe. Educação, antes de mais nada é um ato de interação humana.

\section{Saber curricular}

Uma disciplina não é ensinada conforme entendimento exclusivo do professor sobre o que é necessário ou não ser ministrado, ela é fruto da plena discussão por outros agentes internos e externos da escola até se tornar de forma concreta um programa de ensino. Desta forma, a escola seleciona e estrutura um conjunto de conteúdos redigidos em um ementário, com objetivos, conteúdos e métodos que serão operacionalizados pelos professores com atenção a um programa escolar. (Gauthier et al. 2006: 30) Para Tardif e Lessard 
Os programas escolares também são instrumentos cognitivos úteis que permitem aos professores organizar sua ação em função de objetivos, de expectativas, de sequências, de cronograma. Sem os programas, o ensino atual perderia sua unidade; além disso, cada professor teria que inventar integralmente seu planejamento, sua didática, seus objetivos, etc., a cada vez. (Tardif, Lessard, 2011:207)

Desta forma, educar trata-se de um processo intencional, de uma atividade planejada e estruturada, sem espaço para amadorismo, pois, a escola necessita promover ações orquestradas por meio de um planejamento coletivo, que articule a construção de uma matriz curricular coesa e interdisciplinar, que não irá dissolver o saber científico em um mosaico, onde cada pedaço está em desarmonia com o conjunto da obra. (Tardif, 2008: 223)

Diante de tão importante saber, surpreendeu-nos que somente um aluno mencionou a questão do programa em sua descrição de bom professor. Para o aluno A59 o bom professor consegue apresentar «todo o conteúdo programático da matéria». A análise deste depoimento com base em Tardif e Lessard (2011:207) nos evidencia que o bom professor necessita seguir o programa da disciplina para conferir uma unidade dos pontos articulados no decorrer das aulas, o que contribui para uma homogeneização das práticas escolares, contudo a interpretação e adaptação são necessárias em face das situações diárias vividas em cada contexto escolar.

Aliás, o trabalho do professor perpassa por intermediar o programa de ensino oficial com uma clara visão de tempo e recursos disponíveis. Ele respeita o espírito do programa, mas mantém íntegra sua autonomia e controle do seu trabalho, sem engessar ou burocratizar os conteúdos dialogados em sala.

Cumpre frisar, que na visão dos alunos o saber curricular não recebeu destaque na prática do bom professor o que reforça o entendimento de que vivemos na era do consumismo e «os saberes são bens de consumo, os mestres devem vender as disciplinas que ensinam a alunos que exercem o poder de consumidores, muitas vezes, em função do valor de utilidade das disciplinas.» (Tardif, Lessard, 2011:147)

A sociedade industrial tem exercido grande pressão nos discentes, pois para ser competitivo o aluno busca nos bancos escolares uma máxima racionalização do ensino ao ponto de almejar um curso superior que seja pragmático, eficiente e instrumental voltado para atender exclusivamente a lógica do mercado.

\section{Neste cenário}

A função dos professores não consiste mais, talvez, em formar indivíduos segundo a velha imagem orgânica da cultura geral, mas equipá-los, prevendo a impiedosa concorrência do mercado de trabalho numa sociedade totalmente orientada para o funcional e útil. (Tardif, Lessard, 2011:147)

As mudanças orquestradas pelo mercado de trabalho tem imposto um olhar 
mecânico e utilitarista nos alunos o que se comprova com a diminuta preocupação destes como programa de ensino e o currículo ofertado pela escola, bem como tem provocado o afastamento da escola do seu antigo papel de promovedor de cultura, para ser tão somente um ambiente repleto de disciplinas.

\section{O saber experiencial}

Diferente de outras profissões, os professores entram em contato com sua área de atuação muito antes de iniciar sua vida profissional. Tendo em vista que a prática de ensinar foi presenciada enquanto ainda eram alunos, desta forma os saberes experienciais, em especial os mobilizados nas relações aluno-professor, são provenientes de sua própria história de vida, de sua caminhada dentro e fora do contexto escolar.

Ademais, os professores recorrem muitas vezes às lembranças de suas experiências no ambiente escolar para solucionar acontecimentos em sala de aula, pois o «saber experiencial, se transforma muito cedo em certezas profissionais, em truques do ofício, em rotinas, em modelos de gestão da classe e de transmissão da matéria». (Tardif, 2000:14)

Mais adiante, Tardif para concluir sobre as características do saber experiencial nos evidencia que

[...] É um saber interativo, mobilizado e modelado no âmbito de interações entre o professor e os outros atores educativos. Ele traz, portanto, as marcas dessas interações analisadas anteriormente. Por exemplo, ele está impregnado de normatividade e de afetividade e recorre a procedimentos de interpretação de situações rápidas, instáveis, complexas, etc. (Tardif, 2009:109)

Nesse contexto, essa habilidade de interação exige dos professores a capacidade de se comportarem como sujeitos, como atores e de serem pessoas em interação com outras pessoas, pois a escola é um espaço de múltiplas relações onde diferentes sujeitos deixam suas marcas, valores e singularidades. Neste sentido, o bom professor dispõe de habilidades que estão relacionadas ao cuidado à dimensão emocional e social dos alunos, em que se faz necessária uma «boa dose de envolvimento, dedicação e preocupação com os alunos». (Marchesi, 2008:25)

Como veremos mais adiante, os dizeres dos alunos investigados reforçam claramente a necessidade do relacionamento cordial, afetivo entre professores e alunos, pois, os saberes experienciais são aqueles adquiridos e consolidados por meio da prática cotidiana da profissão docente e não provêm dos cursos de formação ou currículos, provêm da relação dos docentes com o mundo, o seu trabalho, dentro da escola, na sala de aula, com os alunos e na interação com os outros professores.(Tardif y Lessard, 2011:264)

Aliás, nas atividades do contexto escolar o professor dificilmente atua sozinho 
[...] Ele se encontra em relação com outras pessoas, a começar pelos alunos, ou seja, a atividade docente não é sobre um objeto, sobre um fenômeno a ser conhecido ou uma obra a ser produzida. Ela é realizada concretamente numa rede de interações com outras pessoas, num contexto onde o elemento humano é determinante e dominante e onde estão presentes símbolos, valores, sentimentos, atitudes, que são passiveis de interpretações e decisões que possuem geralmente, um caráter de urgência. Essas interações são mediadas por diversos canais: discurso, comportamentos, maneiras de ser etc. (Tardif, 2009:49)

Nessa perspectiva, as relações afetivas são fundamentais para estabelecer um ambiente favorável à construção de conhecimentos, pois, na sua «atividade de ensinar, o professor deve ser respeitoso com as diferentes alternativas sociais, políticas, morais e religiosas que se apresentam na sociedade e que seus alunos vivenciam». (Marchesi, 2008:25)

No entanto, é preciso ressaltar que os saberes do professor não são mensuráveis entre si, ou seja, são constituídos de diferentes formas e se manifestam numa pluralidade de ações que vão estruturando a prática diária. Na verdade, ainda de acordo com Tardif (2009:52-53), os saberes docentes trazem à tona, no próprio exercício do trabalho.

Assim, o professor mobiliza diversos saberes que são construídos ao longo de sua vida, saberes estes que são construídos muito antes de assumir uma sala de aula, ou seja, o que se pode perceber é que o docente inicia a construção de sua identidade profissional a partir das experiências que teve como aluno. Isso faz com que reelabore suas experiências transformando-as em saberes que serão mobilizados no decorrer de sua prática, dentre esses saberes podemos perceber a mobilização do saber experiencial.

A mobilização desta categoria de saber é revelada nas relações estabelecidas entre aluno e professor como demonstram os relatos dos sujeitos que apontaram a dimensão afetiva e emocional como característica do bom professor.

Os dizeres dos alunos possibilitam inferir que um dos requisitos do professor ter sido lembrado foi por conta da sua simpatia, camaradagem, empatia, bom humor, respeito, amizade, carisma, solidariedade e compreensão, o que favorece um maior envolvimento dos alunos com a disciplina e com conteúdos trabalhados em aula.

Neste sentido, para o aluno A2 o bom professor é um ser humano simpático e agradável «[...] não é aquele tipo de professor que só pensa em dificultar a vida do acadêmico. Além de excelente professor em sala, é uma pessoa muito simpática com todos.» Marchesi esclarece que «em qualquer época histórica as emoções sempre ocuparam um papel relevante no mundo do ensino, nos tempos atuais sua importância é ainda maior». (Marchesi, 2008:103) O autor destaca ainda que o modelo social em que vivemos transforma os homens em máquinas pensantes, sujeitos cada vez mais isolados uns dos outros, desta forma a dimensão afetiva-emocional é fundamental no 
contexto escolar.

Para Marchesi (2008:103), «sem dúvida, o ensino é um trabalho emocional» o que fica evidente nos dizeres do aluno $\mathrm{A}_{3}$, pois para ele o bom professor possui

[...] empatia (ele é um ser humano 10), camaradagem (um dia ele foi aluno), tem didática (sabe fazer-se entender), tem bom humor (o lúdico fica gravado), tem respeito (sabe cobrar, aceita ser cobrado), é solidário (nem sempre o aluno vai mal porque não sabe), é inteligente (sabe o momento de criticar).

$\mathrm{O}$ aluno $\mathrm{A} 3$ reforça a necessidade de elementos como: empatia, camaradagem, bom humor, respeito e solidariedade, que se tornam componentes fundamentais para o bom andamento dos trabalhos desenvolvidos pelo docente no ambiente escolar. Tardif e Lessard esclarecem que «ensinar é trabalhar com seres humanos, sobre seres humanos, para seres humanos.» (Tardig, Lessard, 2011:35). Além disso, a docência

[...] é um trabalho cujo objetivo não é constituído de matéria inerte ou de símbolos, mas de relações humanas com pessoas capazes de iniciativa e dotadas de uma certa capacidade de resistir ou participar da ação dos professores. [...] O fato de trabalhar com seres humanos, portanto, não é um fenômeno insignificante ou periférico na análise da atividade docente: trata-se, pelo contrário, do âmago das relações interativas entre os trabalhadores e os 'trabalhados' que irradia sobre todas as outras funções e dimensões do métier. (Tardig, Lessard, 2011:35)

Ao tornar as aulas mais agradáveis com seu senso de humor, o bom professor realiza uma estratégia diferenciada para o desenvolvimento do conteúdo, visando motivar e despertar o interesse dos discentes. Desta forma, incentiva a postura positiva do aluno em aula, favorecendo a relação deste com o conhecimento. O que se evidencia pelo dizer do aluno $\mathrm{A}_{5}$, quando descreve que o bom professor "é dinâmico, ensina 'brincando'. Seu bom humor, educação e principalmente respeito com os alunos faz dele o melhor. Se todos os professores seguissem a linha de ensino dele haveria vontade de ir à aula e estudar.» Depoimentos como estes revelam como o aluno, ao ser afetado positivamente pela prática pedagógica do professor, retribui com uma demonstração de interesse em permanecer no espaço escolar e estudar.

Marchesi deixa claro que

[...] A evidência empírica comprova que os sistemas cognitivos e afetivos estão intimamente relacionados e que não é simples separá-los no seu funcionamento adaptativo. A razão não age em paralelo com a emoção, que supostamente deve controlar e dominar, mas sim as emoções orientam a razão, proporcionando sensibilidade, direção e prioridade. (Marchesi, 2008:102-103)

Os alunos reforçam a importância da dimensão afetiva, pois, não basta saber transmitir o conteúdo. É necessário ter «humanidade», sem preconceitos, ser bem- 
humorado, educado e atencioso conforme relata o aluno A11. Na mesma direção, o aluno $\mathrm{A}_{3} 8$ aponta que o «bom professor» é aquele que «além de dominar o assunto, a sua aula é bem preparada e dinâmica, ele sabe cobrar dos alunos o completo respeito de forma tranquila e com senso de humor incrível.» Nesse sentido, Marchesi esclarece que

[...] A ação educativa não é simplesmente uma atividade técnica, que pode se repetir uma e outra vez, praticamente sem se refletir, nem uma ação desprovida de comunicação e de contato social. Exige, ao contrário, uma estreita e confiada relação pessoal entre professor e alunos, a qual não pode se desenvolver de forma satisfatória sem a consciência por parte dos docentes dos objetivos que se pretende alcançar. (Marchesi, 2008:127)

No entanto, não podemos ignorar que para motivar o aluno, o professor precisa ser referência, demonstrando que conhecer o objeto de estudo pode ser bom e prazeroso, ou seja, demonstrando o significado e o sentido que tal objeto tem para ele e para a ciência jurídica. O que se evidencia pelo relato do aluno A17 "[...] ele sabe passar com clareza o conteúdo, deixa o aluno participar da aula, enfim, é um grande amigo da turma e o melhor professor.»

Marchesi (2008:108-109) afirma que a razão tem origem na emoção. Nesse sentido, uma das tarefas do professor é motivar o aluno, despertar seu interesse, emocioná-lo, afetar o seu pensamento, pois, ensinar é uma ação planejada e intencional, no qual o professor deve buscar instrumentos adequados para afetar de maneira positiva os seus alunos, considerando as especificidades de cada contexto escolar.

Afeto e cognição caminham juntos, por isso o bom professor não se preocupa somente em desenvolver conteúdos. Ele não nega a ciência e a razão, mas cuida com toda dedicação do espaço acadêmico transformando-o em um ambiente acolhedor. Motivar alguém requer interação com a pessoa; isto significa que é necessário respeitá-la e acolhê-la levando-a a desenvolver meios de superação de suas limitações. Conforme relata o aluno A45:

«[...] mesmo percebendo a dificuldade que o aluno tem em sua matéria, não desiste dele. Cobra dos alunos a ponto de fazê-los buscar extraclasse mais conhecimentos. Ele me fez entender a matéria e gostar dela.» Fica evidenciado que as pessoas são afetadas não só por aquilo que o outro faz, mas também pela maneira como faz, seja por meio do incentivo ou de instigar a busca pela superação dos seus limites. Tardif e Lessard entendem que «um professor não trabalha sobre os alunos, mas com e para os alunos, e precisa preocupar-se com eles. Ademais, para um bom número de professores, a opção por essa profissão é resultado de uma vontade de ajudar os jovens, as crianças.» (Tardif, Lessard, 2011:70)

Para o aluno A47, é imprescindível que o docente conquiste o respeito e admiração dos alunos, «[...] pois, quando os alunos não respeitam ou não gostam do pro- 
fessor a aula não será produtiva e a absorção de conhecimento não será a esperada.» Percebemos que o respeito mútuo é um dos ingredientes para a aprendizagem em especial tendo em vista que

[...] Os professores investem muito, emocionalmente falando, em seu trabalho: trata-se de um trabalho emocional «consumidor» de uma boa dose de energia afetiva, e decorrente da natureza interpessoal das relações professor/aluno. Na verdade, dificilmente os professores podem ensinar se os alunos não «gostarem» deles ou, pelo menos, não os respeitarem. Desse modo, suscitar esse sentimento dos alunos é uma parte importante do trabalho. (Tardif, Lessard, 2011:159)

O que fica evidente é que o trabalho docente é forjado por um alto investimento emocional cercado por um constante julgamento de valores, ações e comportamento de si próprio, de seus pares e dos alunos. Assim, buscar o aperfeiçoamento afetivoemocional é um valioso patrimônio que conduz a excelência profissional e a felicidade pessoal do professor.

\section{Considerações finais}

Os saberes docentes não provêm de uma única fonte, mas de várias fontes e de diferentes momentos da trajetória profissional do professor. Na visão dos alunos os saberes docentes possuem uma função de utilidade no ensino, visto que, os saberes pedagógicos, disciplinares, curriculares e experienciais foram apontados na construção da imagem do bom professor.

Chamamos atenção, para o fato de que nenhum aspecto sobre o currículo, o projeto educativo, ou quiçá a articulação interdisciplinar, foi anotada pelos alunos, para eles esta não é uma dimensão relevante na prática profissional do bom professor, o que deixa espaço para uma visão utilitarista, imediatista e pragmática da educação, privilegiando uma máxima racionalização da graduação como uma ferramenta quase que exclusiva para atender aos rigores e a lógica do mercado.

Para os discentes, o bom professor deve saber o quê ensinar, mas também saber como ensinar e deve se lembrar que ensinar não se trata de transferir conhecimento, mas «é fundamentalmente pensar certo - é uma postura exigente, difícil, às vezes penosa, que temos que assumir diante dos outros e com os outros, em face do mundo e dos fatos, antes nós mesmos.». (Freire, 2009:49)

Outro ponto importante trata-se de que o trabalho do bom professor na percepção dos alunos investigados possui um forte componente afetivo-emocional, no qual o saber da experiência se evidencia com um dos saberes docentes presentes na prática diária do professor, sendo o núcleo de todos os outros saberes. «Dito de outra forma, para um docente experiente, esses outros saberes também são incorporados à sua própria experiência do ofício e acabam por formar com ela um só todo.» (Tardif, 
2009:32)

Pelos dizeres dos alunos se infere que a relação afetiva-emocional é de grande importância na prática do bom professor, pois, esta dimensão é tão vital quanto os conhecimentos científicos, as estratégias de aprendizagem, o compromisso social e moral dos docentes. Uma vez que o objetivo da academia é formar sujeitos autônomos, críticos, éticos e responsáveis, a dimensão emocional é fundamental para o desenvolvimento de todo sujeito, pois a afetividade contribui para o desenvolvimento do ser humano e não se resume só a manifestações de carinho físico, mas principalmente em uma preparação de natureza cognitiva para os tempos atuais.

Ademais, a atividade docente se dá em um ambiente onde não se trabalha tão somente com objetos, máquinas e equipamentos, mas sim com sujeitos, com seres humanos, portanto, os saberes docentes são fundamentais neste contexto múltiplo, complexo, instável, impregnado de crenças, culturas, conhecimentos e inquietações das mais diversas.

O processo educacional é formado por interações humanas e a prática do bom professor, requer a formação de um vínculo social de confiança entre os sujeitos envolvidos, pois na visão dos alunos o bom professor mobiliza saberes plurais, oriundos de sua história de vida, de sua experiência pessoal e profissional que é acumulada dentro e fora do ambiente escolar.

\section{Referências}

BAdiA, Antoni, and Francisco Gómez (2014). «Educational Context Conditions Affecting the Teaching Design of University Teacher.» Educacion $X_{1} 17$ (2): 169-192.

Casero Martínez, Antonio (2010). « ¿ Cómo es el buen profesor universitario según el alumnado?.» Revista española de pedagogía 68 (246): 223-242

Freire, Paulo (2009). Pedagogia da autonomia: saberes necessários à prática educativa. $40^{a}$ reimpressão. Rio de Janeiro: Paz e Terra.

Gauthier, Clermont, Stéphane Martineau, Jean-François Desbiens, Annie Malo, Denis Simard (2006). Por uma teoria da Pedagogia. Pesquisas contemporâneas sobre o saber docente. Rio Grande do Sul: Editora Unijuí.

MAS-Torelló, Òscar. (2016). «La influencia de la experiencia en las competencias investigadoras del profesor universitário». Revista Complutense de Educación, 27(1): 13-34.

MARCHESI, Álvaro (2008). O bem-estar dos professores: competências, emoções e valores. Tradução Naila Tosca de Freitas - Porto Alegre: Artmed.

NóvoA, António (2009). Professores imagens do futuro presente. Lisboa: Educa.

PÉrez Sola, Nicolás (2017). «El derecho deber de protección del medio ambiente» Revista de Derecho Político, 1(100): 949-986. 
Roncancio, Jhon Jairo Bejarano, Fabiola Becerra Bulla, and Diana Patricia Escobar Gutiérrez (2013). «Las prácticas de enseñanza del profesor universitario, una herramienta efectiva para el éxito pedagógico.» Revista de la Facultad de Medicina 61 (3): 315-320.

SACristán, José Gimeno (1998). O currículo: uma reflexão sobre a prática. 3. ed. Porto Alegre: Artmed.

Silva Júnior, Joao do Reis., D. Schugurensky, and J. B. D. Araujo (2015). «Ciencia Académica, Intelectuales y el trabajo del profesor universitario en Brasil: convergencia y hegemonía.» Revista de la Educacion Superior 44 (173): 157-79.

TARDIF, Maurice (2000). «Saberes profissionais dos professores e conhecimentos universitários. Elementos para uma epistemologia da prática profissional dos professores e suas conseqüências em relação à formação para o magistério». Revista Brasileira de Educação, ANPED, São Paulo, 13: 5-24.

TARDIF, Maurice (2008). Saberes docentes e formação profissional. Petrópolis: Editora Vozes.

TARDif, Maurice (2009). Trabalho do professor e saberes docentes. Organizado por Romilda Teodora Ens, Dilmeire Sant'Anna Ramos Vosgerau, Marilda Aparecida Behrens. Curitiba, PR: Champagnat.

TARDIF, Maurice; Lessard, Claude (2011). O trabalho docente. Elementos para uma teoria da docência como profissão de interações humanas. Petrópolis, RJ: Vozes.

ToRELLó, Óscar (2014). «Las competencias investigadoras del profesor universitario: la percepción del propio protagonista, de los alumnos y de los expertos». Profesorado. Revista de Currículum y Formación de Profesorado, 18(3): 255-273.

\section{Sobre o autor}

Adilson José Ribeiro. Graduado em Direito pela Associação Catarinense de Ensino, com Mestrado em Educação pela Universidade Regional de Blumenau - FURB. Docente do Curso de Direito da Faculdade Metropolitana de Guaramirim - UNIASSELVI/FAMEG e advogado. E-mail: <adilsonjribeiro1@gmail.com>.

Rita Buzzi Rausch. Doutora em Educação pela Universidade Estadual de Campinas - UNICAMP. Diretora e pesquisadora do Centro de Ciências da Educação, Artes e Letras da Universidade Regional de Blumenau - FURB. E-mail: <ritabuzzirausch@ gmail.com>. 
